\title{
Decidualization in the post-partum uterus of the mouse
}

\author{
Janet M. Brandon \\ Department of Zoology, University of Oxford, South Parks Road, Oxford OXI 3PS, UK
}

\begin{abstract}
Summary. Unilaterally ovariectomized mice were allowed to complete one pregnancy before the second ovary was removed and sensitivity to decidualization was induced by hormone administration. The virgin uterine horn and the post-partum horn were stimulated to decidualize by the intraluminal injection of arachis oil. A greater decidual response was found in post-partum horns than in virgin horns. The foci of decidual induction in post-partum horns were regularly spaced reflecting the regular spacing of used and unused areas of the uterus. A focus of decidual induction occurred in $68 \%$ of the recently used uterine areas observed, i.e. areas associated with post-partum nodules. When compared with foci of decidualization in adjacent unused areas of the uterus, none of the decidualized used zones showed more decidual tissue, about half showed less decidual tissue and half showed the same amount of decidual tissue. The remaining $32 \%$ of used zones were not associated with foci of decidual induction. The results indicate that decidualization can be induced in recently used zones of the uterus using a non-traumatic method of induction, but that used zones are associated with less decidual tissue than unused zones of the post-partum uterus.
\end{abstract}

Keywords: decidualization; post-partum phenomena; mouse

\section{Introduction}

Gross examination of the post-parturient uterus of many rodents, including the common laboratory species, will reveal the presence of discrete pigmented nodules along the uterine-mesometrial boundary (Selye \& McKeown, 1935; Deno, 1937). Each nodule overlies a site of placental detachment at parturition, or the site of the resorption of a feto-placental unit or decidualized implantation site (Conaway, 1955). These nodules are often called 'placental scars' and may persist for many months post partum, perhaps even the lifespan of a rodent (Selye \& McKeown, 1935; Davis \& Emlen, 1948). The colour of the nodules derives from the presence of haemosiderin-laden cells, probably macrophages, which may persist after the disappearance of any overt swelling (Deno, 1937). The structure and function of post-partum uterine mesometrial nodules has aroused little interest since the original descriptive work despite the observations of Momberg \& Conaway (1956), in the rat, and Orsini (1962), in the hamster, that implantations of a second pregnancy occur between, not overlapping with, the nodules derived from the first pregnancy. Nerquaye-Tetteh (1986) extended this observation to the bank vole, Clethrionomys glareolus, in which these nodules are particularly prominent, and found that trauma-induced decidualization could be induced more reliably, and with a greater response, when the trauma was applied on, rather than between, nodules derived from a preceding pregnancy.

The present study was initiated to investigate the relationship between post-partum nodules and subsequent decidualization in an animal in which decidualization could be induced reliably using a non-traumatic method of induction with the potential to stimulate all areas of the uterus equally. The intraluminal instillation of arachis oil was chosen to induce decidualization in the hormonetreated uterus of the ovariectomized laboratory mouse (Finn, 1966). 


\section{Materials and Methods}

Animals and tissues. Virgin female CD-1 mice, obtained either from Charles River UK Ltd (Margate, Kent, UK) or from the colony maintained in this department, were housed in $12 \mathrm{~h}$ light: $12 \mathrm{~h}$ darkness with food and water available at all times. Animals were entered into the experiment at about 8 weeks of age with a body weight of at least $20 \mathrm{~g}$. All surgery was performed under Avertin anaesthesia (2.5 g 2,2,2-tribromoethanol in $5 \mathrm{ml}$ 2-methyl-2-butanol added to $200 \mathrm{ml}$ water and given intraperitoneally at $0.1 \mathrm{ml} / 5 \mathrm{~g}$ body weight). Animals were unilaterally ovariectomized and allowed to recover for 1-4 days before being placed with CD-1 males for 1 week. Inequality of reproductive function between left and right uterine horns in the mouse has been reported by Wiebold \& Becker (1987). To avoid any bias towards the left or right uterine horns, with regard to the number of implantations maintained in the unilateral pregnancy or to the success of the subsequent induction of decidualization, the side of initial ovariectomy was alternated, so when the left ovary was removed from one animal, the right ovary was removed from the next animal, and so on. Not all unilaterally ovariectomized animals became pregnant, but no difference was observed in this regard between the two sides. Pregnant females were observed once daily from the earliest expected time of parturition. The day on the morning of which a litter was found was designated Day I post partum. Litters were removed and killed by carbon dioxide asphyxiation on Day 1, and the second ovary was removed on Day 1, or occasionally Day 2, post partum. Hormone treatment was started 1-7 days after the second ovariectomy. The hormones were obtained from Sigma Chemical Co. Ltd (Poole, Dorset, UK) and given subcutaneously in $0.1 \mathrm{ml}$ arachis oil. The treatment regimen used was based on that used by Pollard \& Finn (1972): $100 \mathrm{ng}$ oestradiol-17 $\beta$ /mouse for 3 days; rest for 2 days; then $1 \mathrm{mg}$ progesterone/mouse plus $10 \mathrm{ng}$ oestradiol/mouse for 3 days with the induction of decidualization 5-6 h after the third injection; then $1 \mathrm{mg}$ progesterone/mouse daily until the animals were killed by cervical dislocation. Decidualization was induced by the injection into each horn of $10 \mu$ arachis oil using a 30-gauge needle inserted near the uterotubal junction. The left uterine horn was always injected first. Animals were killed 20, 44, 68 or $92 \mathrm{~h}$ after decidual induction. The day post partum on which animals were killed ranged from Day 10 to Day 18 . Some animals were given the hormone treatment but were not stimulated to decidualize, or given a sham operation, and were killed at the equivalent of $68 \mathrm{~h}$ after decidual induction. These animals are presented as hormone-treated controls.

Uteri were removed and weighed. Each horn was pinned, straight but not stretched, onto foil-covered card using the oviduct and cervix as anchorage points and fixed in acetyl formol alcohol (glacial acetic acid:40\% $\mathrm{w} / \mathrm{v}$ formaldehyde:absolute ethanol:distilled water; 1:1:3:5, by vol.). The uteri were dehydrated, bleached and cleared according to the method of Orsini (1962) with some modifications. Uteri were stored and examined in benzyl benzoate. The length of cleared uterine horns was measured. The measurement so obtained cannot be considered to represent the actual length of the horns in vivo, but since all uteri were treated similarly and the author conducted all procedures the measure of length obtained can be considered to be comparable between and within animals.

All uteri were examined under low magnification $(\times 6 \times 25)$ to define the position of post-partum uterine mesometrial nodules in relation to areas of decidual tissue. Decidual tissue was visible as opaque swellings along the length of the horn in cleared uteri. Initial examinations led to the description of 5 categories to define the spatial relationships between nodules and decidual tissue. These categories are described in the 'Results' section. Since the assignment of nodules to categories involved a degree of subjective judgement, the categorizations reported here were conducted by the author all on the same day and without reference to any previous description of the nodules.

Pieces of uterus taken for histological examination were embedded in paraffin wax, sectioned at $7 \mu \mathrm{m}$, and stained with haematoxylin and eosin.

Presentation of data and statistical analyses. The design of this study allowed the comparison between a decidualized uterine horn which had not previously held a pregnancy (to be referred to as the virgin horn) and a decidualized uterine horn which had recently held a pregnancy (to be referred to as the post-partum horn) to be made within each animal. The paired ' $t$ ' test was used to test the significance of differences between the uterine horns. The value entered into this test is $h$, the difference between a pair, and the analysis of horn weights and lengths by this method is presented in Table 1 . The values of $h$ do not convey the change in horn weights and lengths with time after decidualization, and so the actual values for horn weights and lengths were used to calculate correlation coefficients $(r)$ and to define the linear regressions of weight and length with time (Fig. la, Ib). The distribution of nodules into various categories with regard to the spatial relationship between nodules and decidual tissue was analysed using the $\chi^{2}$ test.

\section{Results}

\section{Uterine horn weight and length}

The wet weight increased linearly with time after decidual induction in both virgin $(r=0.624$, $P<0.001)$ and post-partum $(r=0.815, P<0.001)$ horns (Fig. 1a). The rate of the increase in uterine horn weight was greater in post-partum horns than in virgin horns (slope of regression $5 \cdot 24$ vs 3.46). Within any one animal, the post-partum horn was invariably heavier than the virgin horn. The difference in weight between the horns was statistically significant in all groups (Table 1). 
Table 1. The difference between the post-partum and virgin uterine horns for weight and length, in control animals and at intervals after decidual induction

\begin{tabular}{lccc}
\hline & & \multicolumn{2}{c}{$\begin{array}{c}\text { Difference between post-partum } \\
\text { and virgin horns (mean } \pm \text { s.e.m.) }\end{array}$} \\
\cline { 3 - 4 } & No. of & Weight $(\mathrm{mg})$ & Length $(\mathrm{mm})$ \\
\cline { 3 - 4 } & & & \\
\hline Control & 4 & $25 \cdot 0 \pm 5 \cdot 0^{*}$ & $9 \cdot 2 \pm 1 \cdot 7^{*}$ \\
$20 \mathrm{~h}$ & 4 & $57 \cdot 5 \pm 14^{* *}$ & $14 \cdot 0 \pm 1 \cdot 7^{*}$ \\
$44 \mathrm{~h}$ & 6 & $83 \cdot 3 \pm 13 \cdot 1^{* *}$ & $10 \cdot 2 \pm 1 \cdot 7^{* *}$ \\
$68 \mathrm{~h}$ & 11 & $156 \cdot 4 \pm 21 \cdot 8^{* * *}$ & $8 \cdot 4 \pm 1 \cdot 7^{* * *}$ \\
$92 \mathrm{~h}$ & 8 & $167 \cdot 5 \pm 27 \cdot 7^{* * *}$ & $11 \cdot 6 \pm 2 \cdot 2^{* *}$ \\
\hline
\end{tabular}

${ }^{*} P<0.05 ;{ }^{* *} P<0.01 ;{ }^{* *} P<0.001$ (paired $t$ tests).

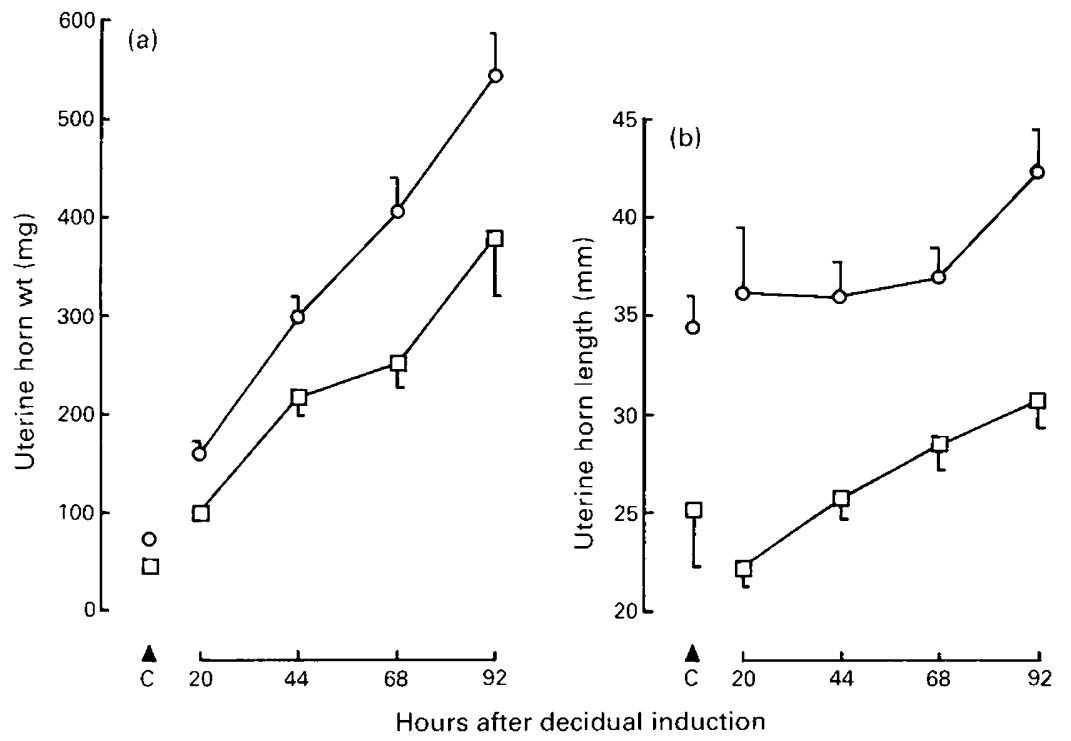

Fig. 1. The change in uterine horn weight (a) and length (b) in mice with time after decidual induction. [] , virgin horns; $O$, post-partum horns; $\mathbf{C}$, hormone-treated control uteri. Values are mean \pm s.e.m. for the number of animals indicated in Table 1. The statistical differences calculated can also be found in Table 1 .

The length of the uterine horns increased linearly with time after decidual induction in both virgin $(r=0.623, P<0.001)$ and post-partum $(r=0.383, P<0.05)$ horns (Fig. $1 \mathrm{~b})$. The rate of change in uterine length was similar in post-partum and virgin horns (slope of regression 0.09 and 0.11 respectively). Within any one animal, the post-partum horn was invariably longer than the virgin horn. The difference in length between the horns was statistically significant in all groups (Table 1).

These data were analysed as $\mathrm{mg}$ uterine horn weight per $\mathrm{mm}$ uterine horn length $(\mathrm{mg} / \mathrm{mm})$ to determine whether the greater weight of post-partum horns could be attributed to the greater length available for decidualization. If this were so, the statistic $\mathrm{mg} / \mathrm{mm}$ would not vary between post-partum and virgin horns. However, the difference in the rate of increase in uterine weight for post-partum and virgin horns (Fig. la) would suggest that $\mathrm{mg} / \mathrm{mm}$ for post-partum horns would be 
greater than for virgin horns during the growth of decidual tissue. With regard to individual uteri, the statistic $\mathrm{mg} / \mathrm{mm}$ was greater in the post-partum horn than in the virgin horn in $3 / 4$ control uteri, $2 / 4$ at $20 \mathrm{~h}, 4 / 6$ at $44 \mathrm{~h}, 10 / 11$ at $68 \mathrm{~h}$ and $7 / 8$ at $92 \mathrm{~h}$ after decidual induction. The paired ' $t$ ' test was applied and a significant difference was found between the horns at $68 \mathrm{~h}(P<0.001)$, indicating that there was more decidual tissue per unit length of horn in post-partum horns than in virgin horns at this time.

\section{Observations on uterine mesometrial nodules and decidual tissue}

No decidual tissue was seen in cleared uteri from animals killed $20 \mathrm{~h}$ after decidual induction. Histological examination of $20 \mathrm{~h}$ uteri revealed the presence of oedematous swelling of the antimesometrial stroma, causing the lumen to be displaced mesometrially. No recognizable decidual cells were seen in virgin or post-partum horns from $20 \mathrm{~h}$ uteri. Decidual tissue was visible as opaque swellings in cleared uteri taken from animals killed at 44,68 and $92 \mathrm{~h}$ after decidual induction. Histological examination of 44,68 and $92 \mathrm{~h}$ uteri revealed the presence of a typical decidual reaction. Decidualization was not evenly distributed along the length of the uterine horns but occurred as a series of round bead-shaped, and longer sausage-shaped, areas of decidual tissue with undecidualized regions between areas of decidual tissue and at some of the cervical and oviducal ends of horns. A pattern of decidualization best described as a string of beads was predominant in postpartum horns from 44 and $68 \mathrm{~h}$ uteri (13/17, Fig. 2a, b). Post-partum horns from $92 \mathrm{~h}$ uteri showed more irregularity in the size and shape of areas of decidual tissue (Fig. 2c). Virgin horns contained areas of decidual tissue of variable shape and size (Fig. 3).

Each nodule was assigned to one of five categories to describe the spatial relationship between nodules and areas of decidual tissue. Category 1-betweens: nodules found between areas of decidual tissue (Fig. 2b); Category 2-edges: nodules located on the edge of an area of decidual tissue (Fig. 2c); Category 3-undersize: nodules found on areas of decidual tissue which were notably smaller than neighbouring areas of decidual tissue (Fig. 2a, b, c); Category 4-full-size: nodules found on areas of decidual tissue which were not notably different in size compared to neighbouring areas of decidual tissue (Fig. 2a, c); Category 5-others: nodules found in areas of the uterus containing very little or no decidual tissue, and nodules found at the extreme oviducal and cervical ends of horns (Fig. 2b).

All the nodules observed could be allocated to one of these categories without any loss of relevant information. The results of the categorization are given in Table 2.

The distribution of nodules into Category 1 or Category 2 (betweens and edges) did not change from $44 \mathrm{~h}$ to $68 \mathrm{~h}(P>0.05)$ or from $68 \mathrm{~h}$ to $92 \mathrm{~h}(P>0.05)$. Observation of the uteri indicated that Category 2 nodules (edges) represented Category 1 nodules (betweens) that had become involved in the advancing edge of a growing area of decidual tissue. Consequently Categories 1 and 2 were pooled for statistical comparisons with other categories. Nodules in Categories 1,2 and 3 (betweens, edges and undersize) are all associated with a relative lack of decidual tissue compared to adjacent uterine areas and account for $61 \%$ of all nodules observed. Although the overall proportion of nodules assigned to this group of categories did not vary with time after dedicual induction $(62 \%, 60 \%$ and $61 \%$ at 44,68 and $92 \mathrm{~h}$ respectively), the distribution of nodules amongst these categories did vary with time. There was no significant change in the distribution into Categories $(1+2)$ and Category 3 from $44-68 \mathrm{~h}(P>0 \cdot 1)$ but there was a highly significant change from 68 to $92 \mathrm{~h}\left(\chi^{2} 27 \cdot 13, P<0.001\right)$. The proportion of nodules classified as 'undersize' fell from $44 \%$ at $68 \mathrm{~h}$ to $14 \%$ at $92 \mathrm{~h}$, whereas the proportion classified as 'betweens' or 'edges' rose from $16 \%$ to $47 \%$ during this time. This apparent change of Category 3 nodules (undersize) into Category 1 or 2 (betweens and edges) indicates that some areas of decidual tissue which were notably smaller than neighbouring areas either regressed or became incorporated into the edge of larger, more rapidly growing, adjacent areas. The proportion of nodules associated with a relative lack of decidual tissue (Categories 1, 2 and 3), and the porportion associated with full-sized decidual responses 


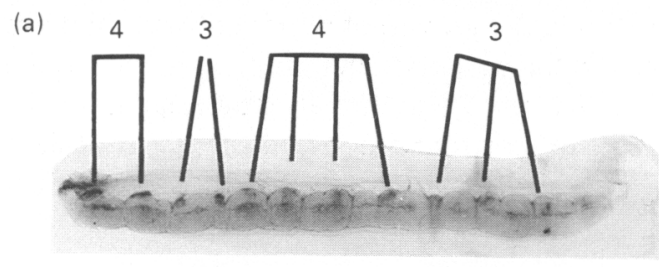

(b)

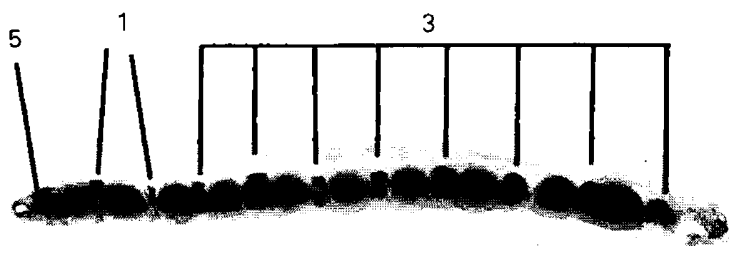

(c)

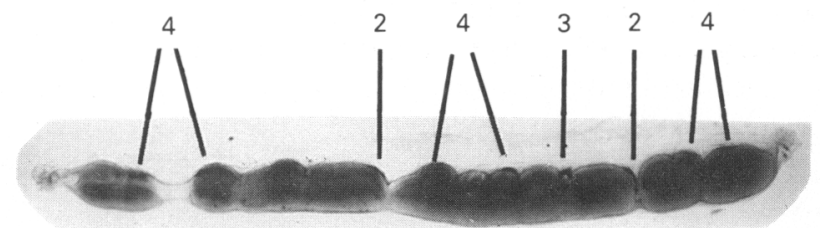

Fig. 2. Post-partum uterine horns taken from mice killed at $44 \mathrm{~h} \mathrm{(a),68} \mathrm{h} \mathrm{(b)} \mathrm{and} 92 \mathrm{~h} \mathrm{(c)} \mathrm{after}$ decidual induction. $\times 1 \cdot 7$. Each uterus is orientated with the mesometrium towards the top of the page. The 'string of beads' effect, due to the regular spacing of foci of decidual induction, which is seen at $44 \mathrm{~h}$ and $68 \mathrm{~h}$ is illustrated in (a) and (b). The association of post-partum nodules with areas of decidual tissue smaller than neighbouring areas is well illustrated in (b). The more uneven growth of decidual tissue found at $92 \mathrm{~h}$ is shown in (c). Not all the postpartum nodules present in these uteri are clearly visible on these photographs but those which are visible have been labelled according to the category to which they were assigned. All the categories described in the text are represented: (1) nodules found between areas of decidual tissue; (2) nodules located on the edge of an area of decidual tissue; (3) nodules found on areas of decidual tissue which were notably smaller than neighbouring areas of decidual tissue; (4) nodules found on areas of decidual tissue which were not notably different in size compared to neighbouring areas; (5) nodules found on areas of the uterus containing very little or no decidual tissue, and nodules found at the extreme oviducal and cervical ends of horns.

(Category 4), did not vary with time after decidual induction (Table 2). This consistent distribution supports the assertion that the categorization was carried out without subjective bias.

Decidualization was initiated within two-thirds of the recently used uterine areas observed, i.e. areas associated with nodules (Categories 3 and 4 , undersize and full-size, $68 \%$ overall). The decidual response was reduced, relative to adjacent unused areas, in $36 \%$ of used areas (Category 3 ), and unchanged, relative to adjacent unused areas, in $32 \%$ of used areas (Category 4). In no instance was the decidual response greater in a used area than in adjacent unused areas. Used areas were not associated with nodes of induction in $32 \%$ of observations (Categories 1,2 and 5). 

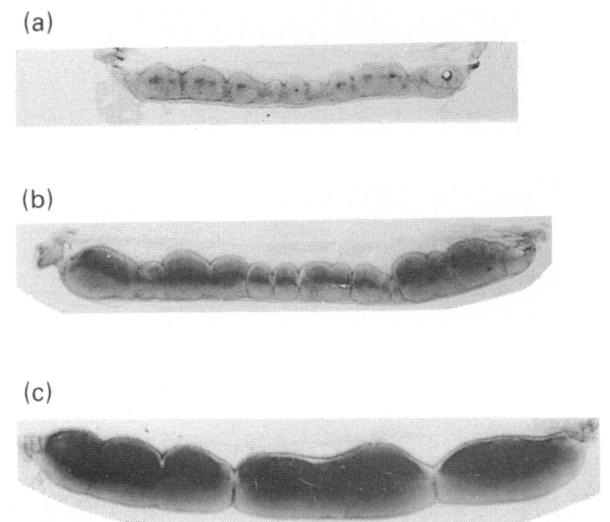

Fig. 3. Virgin uterine horns taken from animals killed at $44 \mathrm{~h}$ (a), $68 \mathrm{~h} \mathrm{(b)}$ and $92 \mathrm{~h} \mathrm{(c)} \mathrm{after}$ decidual induction. $\times 1.7$. Each uterus is orientated with the mesometrium towards the top of the page. The decidual swellings in virgin uteri can be seen to be of uneven size and irregularly spaced along the uterine horn.

Table 2. The categorization of uterine mesometrial nodules found in mouse uteri at intervals after decidual induction

\begin{tabular}{lccccccc}
\hline & & \multicolumn{5}{c}{ Categories*(\%) } \\
\cline { 5 - 8 } Group & $\begin{array}{c}\text { No. of } \\
\text { uteri }\end{array}$ & $\begin{array}{c}\text { No. of } \\
\text { nodules }\end{array}$ & $\begin{array}{c}1 \\
\text { ('betweens') }\end{array}$ & $\begin{array}{c}2 \\
\text { ('edges') }\end{array}$ & $\begin{array}{c}3 \\
\text { ('undersize') }\end{array}$ & $\begin{array}{c}4 \\
\text { ('full-size') }\end{array}$ & $\begin{array}{c}5 \\
\text { ('others') }\end{array}$ \\
\hline $44 \mathrm{~h}$ & 6 & 68 & $2(3)$ & $4(6)$ & $36(53)$ & $23(34)$ & $3(4)$ \\
$68 \mathrm{~h} \dagger$ & 10 & 93 & $10(11)$ & $5(5)$ & $41(44)$ & $33(36)$ & $4(4)$ \\
$92 \mathrm{~h}$ & 8 & 85 & $25(29)$ & $15(18)$ & $12(14)$ & $23(27)$ & $10(12)$ \\
Total & 24 & 246 & $37(15)$ & $24(10)$ & $89(36)$ & $79(32)$ & $17(7)$ \\
\hline
\end{tabular}

* See text for full descriptions.

†One animal was excluded from this group (see Table 1) because the uterus was not available for categorization.

\section{Discussion}

Nerquaye-Tetteh (1986) studied decidualization in the post-partum uterus of the bank vole, Clethrionomys glareolus, a species which shows prominent post-partum uterine mesometrial nodules. Crushing of the uterus was used to induce decidualization in the bank vole since this species does not show a reliable response to intrauterine oil (Nerquaye-Tetteh, 1986). Crushing areas of the uterus between post-partum nodules or crushing a contralateral virgin horn was found to result in smaller and less reliably induced decidual reactions than those resulting from crushing the actual post-partum nodules. The study reported here was designed to investigate the decidual response in recently used and unused areas of the uterus using a well-established experimental system for decidualization which does not rely on traumatization of the uterus to elicit a response (Finn \& Keen, 1963; Hinchliffe \& El-Shershaby, 1975). The results reported here are in agreement with those of Nerquaye-Tetteh (1986) in that decidualization in post-partum horns was found to be greater than that in virgin horns, but the present results disagree with those of Nerquaye-Tetteh (1986) in that decidualization in recently used zones of the uterus, as indicated by the presence of post-partum nodules, was decreased or not changed compared to adjacent unused zones. The postpartum uterus is apparently able to mount a more vigorous decidual response than the virgin uterus 
but, in the mouse, previously unused areas of the uterus contribute more to this response than used areas. Parkes (1928), using uterine trauma to induce decidualization in the mouse, reported that a smaller response could be obtained during lactation, i.e. in a post-partum uterus, than during pseudo-pregnancy, i.e. in a virgin uterus. These conflicting results emphasize the difficulties in comparing studies using different modes of decidual induction.

The injection of oil into the uterine lumen of an appropriately treated mouse does not result in the induction of decidualization evenly along the entire length of the horn but in a series of foci of decidual induction (Hinchliffe \& El-Shershaby, 1975; Lundkvist et al., 1977). These foci of decidual induction grow to give a series of discrete swellings along the length of the horn (Finn \& Hinchliffe, 1964). It is my experience that the induction of decidualization using intrauterine oil results in a series of unevenly-sized, irregularly-spaced decidual swellings at $2-4$ days after induction. This is reflected in the present observations on virgin uterine horns. The presence of post-partum nodules in a uterine horn appeared to alter this pattern of induction to give more evenly-sized, regularlyspaced nodes of decidual induction, the 'string of beads' effect, reflecting the even spacing of used and unused zones along the length of the horn. The even spacing of used sites along the uterus reflects the even spacing of implantation sites which is accomplished by a combination of muscular activity and differential growth (Finn, 1977). Oil injected into the lumen is broken up into droplets some of which become located in the antimesometrial extremity of the lumen, as do blastocysts (Hinchliffe \& El-Shershaby, 1975; Martin, 1979). The post-partum nodule interrupts the continuity of the circular muscle layer in the rodent uterus (Selye \& McKeown, 1935; Deno, 1937) and it is possible that the presence of post-partum nodules could affect the circular muscle contraction which is associated with the antimesometrial placement of oil droplets or blastocysts (Martin, 1979). However, the presence of post-partum nodules could alter local uterine responses in other ways such as by the influence of the many biologically active factors secreted by the macrophages reported to be present in nodules (Deno, 1937). One relevant factor in this context could be prostaglandins. Macrophages are known to secrete prostaglandins (Davies et al., 1980) and prostaglandins have been implicated in the control of implantation and decidualization (Kennedy \& Armstrong, 1981). The observation that implantations of a second pregnancy do not occur in recently used zones of the uterus (rat: Momberg \& Conaway, 1956; hamster: Orsini, 1962; bank vole: Nerquaye-Tetteh, 1986) cannot be accounted for by a failure to initiate decidualization at used sites, although the results reported here do suggest that recently used uterine areas are associated with less decidual tissue than previously unused uterine areas. The histology of decidual tissue associated with used uterine areas will be described in future publications.

This work was undertaken while the author was the Journals of Reproduction and Fertility Ltd Research Fellow. I thank John Clarke for hospitality and helpfulness and Valerie Petts and Janet Evans for preparing histological sections.

\section{References}

Conaway, C.H. (1955) Embryo resorption and placental scar formation in the rat. J. Mammal. 36, 516-532.

Davies, P., Bonney, R.J., Humes, J.L. \& Kuehl, F.A., Jr (1980) The synthesis of arachidonic acid oxygenation products by various mononuclear phagocyte populations. In Mononuclear Phagocytes. Functional Aspects, pp. 1317-1347. Ed. R. van Furth. Martinus Nijhoff Publishers, The Hague.

Davis, D.E. \& Emlen, J.T. (1948) The placental scar as a measure of fertility in rats. J. Wildl. Mgmt 12, $162-166$.

Deno, R.A. (1937) Uterine macrophages in the mouse and their relation to involution. Am. J. Anat. 60, 433-471.
Finn, C.A. (1966) Endocrine control of endometrial sensitivity during the induction of the decidual reaction in the mouse. J. Endocr. 36, 239-248.

Finn, C.A. (1977) Positioning of blastocysts in the uterus. In Biology of the Uterus, ch. 9, pp. 272-273. Ed. R. M. Wynn, Plenum Press, New York.

Finn, C.A. \& Hinchliffe, J.R. (1964) Reaction of the mouse uterus during implantation and deciduoma formation as demonstrated by changes in the distribution of alkaline phosphatase. J. Reprod. Fert. 8, 331-338.

Finn, C.A. \& Keen, P.M. (1963) The induction of deciduomata in the rat. J. Embryol. exp. Morph. 11, 673-682. 
Hinchliffe, J.R. \& El-Shershaby, A.M. (1975) Epithelial cell death in the oil-induced decidual reaction of the pseudopregnant mouse: an ultrastructural study. $J$. Reprod. Fert. 45, 463-468.

Kennedy, T.G. \& Armstrong, D.T. (1981) The role of prostaglandins in endometrial vascular changes at implantation. In Cellular and Molecular Aspects of Implantation, pp. 349-363. Eds S. R. Glasser \& D. W. Bullock. Plenum Press, New York.

Lundkvist, O., Ljungkvist, I. \& Nilsson, O. (1977) Early effects of oil on rat uterine epithelium sensitized for decidual induction. J. Reprod. Fert. 51, 507-509.

Martin, L. (1979) Early cellular changes and circular muscle contraction associated with the induction of decidualization by intrauterine oil in mice. $J$. Reprod. Fert. 55, 135-139.

Momberg, H. \& Conaway, C. (1956) The distribution of placental scars of first and second pregnancies in the rat. J. Embryol. exp. Morph. 4, 376-384.

Nerquaye-Tetteh, J.O. (1986) Endometrial changes associated with implantation in the field vole, Microtus agrestis, and the bank vole. Clethrionomys glareolus. D.Phil. thesis, University of Oxford.

Orsini, M.W. (1962) Study of ovo-implantation in the hamster, rat, mouse, guinea-pig and rabbit in cleared uterine tracts. J. Reprod. Fert. 3, 288-293.

Parkes A.S. (1928) The functions of the corpus luteum. II-The experimental production of placentomata in the mouse. Proc. R. Soc. Lond. B 104, 183-188.

Pollard, R.M. \& Finn, C.A. (1972) Ultrastructure of the uterine epithelium during the hormonal induction of sensitivity and insensitivity to a decidual stimulus in the mouse. J. Endocr. 55, 293-298.

Selye, H. \& McKeown, T. (1935) Studies on the physiology of the maternal placenta in the rat. Proc. $R$. Soc. Lond. B 119, $\mid-31$.

Wiebold, J.L. \& Becker, W.C. (1987) Inequality in function of the right and left ovaries and uterine horns of the mouse. J. Reprod. Fert. 79, 125-134.

Received 24 March 1989 